\title{
Visual content and its teaching-learning process for visually impaired: a big challenge
}

\author{
Lailla M. S. Bine ${ }^{1}$, Álisson R. Svaigen ${ }^{1}$, Wuigor I. S. Bine ${ }^{1}$, \\ Linnyer B. Ruiz ${ }^{1}$ \\ ${ }^{1}$ Departamento de Informática - Universidade Estadual de Maringá (UEM) \\ Maringá - PR - Brazil \\ \{lailla.milainny,alisson.svg\}@gmail.com, \{pg400806, lbruiz\}@uem.br
}

\begin{abstract}
This work presents an survey-based study which aims to understand the experiences and difficulties between teachers and visually impaired (VI) regarding visual content and its teaching-learning process. We also exposed challenges related to assistive technologies which can aid to overcome the teachinglearning barriers. Our study shows an indicative that teachers do not believe they received a proper background to teach VIs in their formation, however, this issue has improved while they have had teaching experiences with VIs. Related to visual content, the assistive technologies which could help them are not proper disseminated. We also discussed that there are several challenges related to these technologies and their applications which remain as opened questions.
\end{abstract}

\section{Introduction}

In teaching-learning environments, there is a big challenge related to provide a proper representation of digital image content to Visually Impaired (VIs) with blindness or severe low vision. The frequent use of graphic and diagrams creates learning barriers [Luque et al. 2017], [Pansanato et al. 2012].

In accordance with Article 5 of the Brazilian Federal Constitution [1988], all individuals are equal, without distinction of any kind, i.e. individuals with visual impairment have the right, as provided by law, to fully participate in society. In this context, inclusive education assumes fundamental importance regarding the limits' elimination faced by individuals with disabilities [Teixeira 2014].

Besides that, students with disabilities have the right to have access to the same resources as all other students. In this context, assistive technologies have been developed as solutions to overcome these barriers, trying to reduce the teaching-learning process lack among students and teachers [Bhowmick and Hazarika 2017].

Before to investigate and to propose any solution in the digital assistive tools context, it is mandatory to understand in this scenario the professors and VI students experiences, which can be expressed according to the following questions: i) How difficult is to teach and to learn a digital image content?; ii) How prepared professors are to teach this kind of content?; iii) How much professors and VI students know about the related assistive digital technologies? It is very important to understand these questions because they can modeling learning environments in social, motivational and affective aspects.

Considering the aforementioned aspects, this work presents an survey-based study which aims to understand the experiences and difficulties between teachers and VI students regarding visual content and its teaching-learning process. This study was carried 
VIII Congresso Brasileiro de Informática na Educação (CBIE 2019)

Anais do XXX Simpósio Brasileiro de Informática na Educação (SBIE 2019)

through questionnaires applied to teachers and VI students. In this work, we also expose challenges assistive technologies which can aid to overcome the teaching-learning barriers.

This paper is organized as follows: Section 2 presents the survey-based study carried in this work, explaining the methodology and the teachers and VI students results; related challenges are exposed and discussed in Section 3; finally, our conclusions are presented in Section 4.

\section{Survey-based Study About Teaching Contents Expressed by Images to VIs}

Before to develop systems and tools which can compose an assistive environment for teaching content using images, it is necessary to investigate the didactic issues in VI teaching-learning process. In the following sections, we present the survey-based study's methodology and results. Our main goal is to investigate how educators have been teaching and adapting their teaching materials which contains visual concepts and how VI students did or do to overcome this barrier.

\subsection{Methodology}

The survey-based study methodology on teaching and learning of contents expressed by images for the VI consists of the following steps:

- Development of two questionnaires: one of them is focused on teachers who have already taught for VIs, and the other is focused on VIs students;

- Research dissemination using the snowballing approach.

The questionnaires were developed using Google Forms. Both studies, for teachers and students, had their questions divided into the following themes:

- Teacher/student profile;

- Teaching/learning experiences;

- Visual content in related subjects;

- Visual content representation tools.

In addition to these themes, the participants could point general comments about their experiences. We used the snowballing approach to disseminate our research. This technique consists of two parts: first, a random sample of individuals is draw from a given finite population. Second, each individual in the sample sends the survey for $k$ different individuals in the population [Goodman 1961].

Furthermore, we selected VI students and teachers (who already had teach to VIs) and we invited them to answer the questionnaire, sending it to other students/teachers who could be a potential participant. It is important to emphasize that with this study it is possible to obtain only teaching-learning indicatives about the treated scenario. Regarding this, a statistical study of greater comprehensiveness and complexity would be necessary.

\subsection{Teachers study}

We obtained 68 teachers answers who already had teach for VIs. Most people who answered are from southern Brazil (70\% - see Fig. 1 part $a$ ). The majority of them have Ph.D (47\% - see Fig. 1 part b), act in public universities (66\% - see Fig. 1 part $c$ ) and they 
VIII Congresso Brasileiro de Informática na Educação (CBIE 2019)

Anais do XXX Simpósio Brasileiro de Informática na Educação (SBIE 2019)

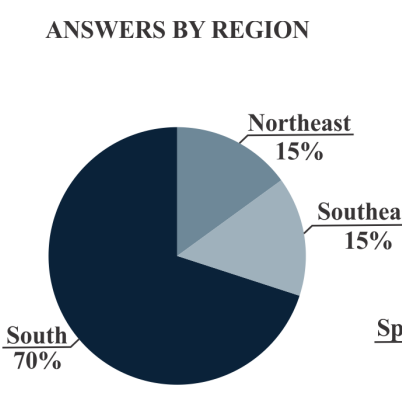

a

ANSWERS BY OCCUPATION AREA

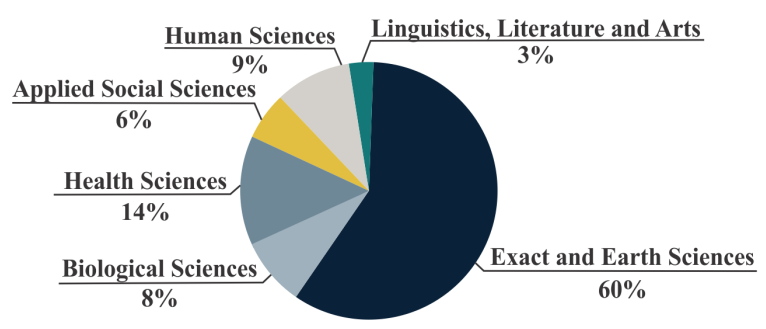

d
ANSWERS BY SCHOLARITY

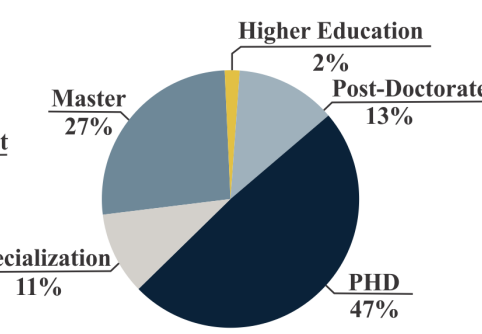

b

ANSWERS BY EDUCATIONAL ENVIRONMENT

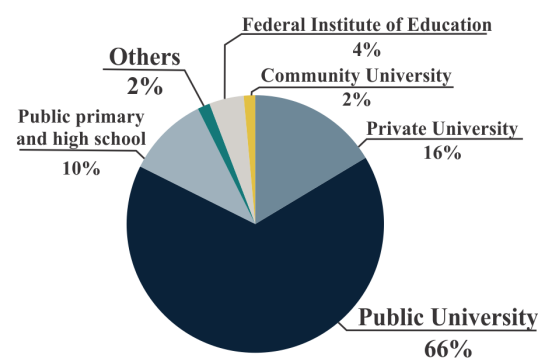

c

ANSWERS BY NUMBER OF VIS

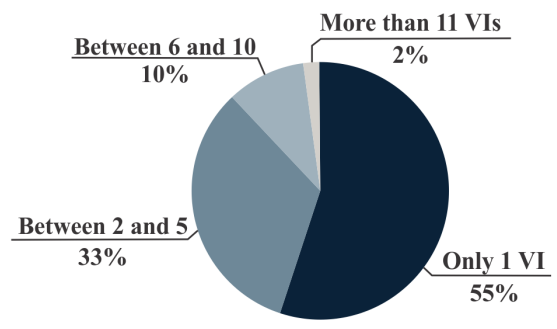

$\mathbf{e}$

Figure 1. Teacher Profile Overview

are from Exact and Earth Science area (60\% - see Fig. 1 part $d$ ). In addition, more than a half of all (55\% - see Fig. 1 part $e)$ taught to 1 VI, only. Fig. 1 shows the teachers profile.

The participants answered 4 questions related to didactic of VI's teaching experiences. Regarding the questions' answers, a Likert-based scale variation was used [Likert 1932]. The response options vary from 1 to 5 (1 - Strongly disagree, 2 - disagree, 3 - Neutral, 4 - Agree 5 - Strongly agree). The four questions were:

- Q1: I find that I was good at teaching VI people, before I had that experience;

- Q2: I find that I was good at teaching VI since I already had this experience;

- Q3: I find that my graduate/ postgraduate courses prepared me to teach visual content to visually impaired;

- Q4: I find that it is difficult to teach visual content to visually impaired.

Regarding the visual content presented in subjects, teachers answered 4 questions. For questions Q5 to Q7 we use the Likert scale. Question Q8 had an open answer.

- Q5: I find that the subjects I taught for visually impaired had a lot of visual content. (explanation and contextualization by graphs, flowcharts, visual models, etc.);

- Q6: I find it difficult to present such content to the VIs so they have the same (or as possible) learning as the sighted.

- Q7: I believe it's difficult for VIs to learn about a particular subject that is expressed by visual content.

- Q8: What alternatives did you find to introduce this kind of content to VIs? 
VIII Congresso Brasileiro de Informática na Educação (CBIE 2019)

Anais do XXX Simpósio Brasileiro de Informática na Educação (SBIE 2019)

We also asked about the participant's questions related to visual content representation tools. For questions Q9 and Q10 we use the Likert scale.

- Q9: I consider that I know auxiliary digital tools for visual content representation for the visually impaired;

- Q10: I believe that such tools are widespread in education environment.

The Figure 2 presents the results overview for the teachers' questionnaire.

\begin{tabular}{|c|c|c|c|c|c|}
\hline \multicolumn{2}{|c|}{ Median } & Disagreement (\%) & \multirow{2}{*}{$\begin{array}{l}\text { Agreement (\%) } \\
4,4\end{array}$} & \multirow{2}{*}{$\begin{array}{c}\text { Neutrality } \\
5,9\end{array}$} & \multirow{10}{*}{$\begin{array}{l}\text { Strongly disagree } \\
\text { Disagree } \\
\text { Neutral } \\
\text { Agree } \\
\text { Strongly agree }\end{array}$} \\
\hline Q1 & & 89,7 & & & \\
\hline Q2 & & 26,5 & 39,7 & 33,8 & \\
\hline Q3 & & 94,1 & 1,5 & 4,4 & \\
\hline Q4 & & 8,8 & 53,8 & 29,4 & \\
\hline Q5 & & 13,2 & 60,3 & 26,5 & \\
\hline Q6 & & 5,9 & 73,5 & 20,6 & \\
\hline Q7 & & 5,9 & 77,9 & 16,2 & \\
\hline Q9 & & 73,5 & 7,3 & 19,1 & \\
\hline Q10 & & 88,2 & 2,9 & 8,8 & \\
\hline
\end{tabular}

Figure 2. Teacher's questionnaire answers

Before having a first contact with the visually impaired (Q1), most answers $(89,7 \%)$ were in the disagreement category, meaning that the participants discord of the statement that they had didactic to teach VI students. After having a first contact with the visually impaired $(\mathrm{Q} 2)$, most answers $(39,7 \%)$ were in the agreement category. This may be indicative that the participants believe that their didactic improved with the experience, but many responses were neutral.

The vast majority of the participants $(94,1 \%)$ answer that they did not receive a proper preparation while graduate/postgraduate course regarding visually impaired teaching (Q3). This may be a outcome indicative of question Q1. Another point (Q4), is that more than a half of all participants $(53,8 \%)$ believe that teaching visual content for VIs is difficult, but in this question we also have a lot of neutral answers.

In questions related to visual content, we have the following results: in Q5, the majority of survey participants $(60,3 \%)$ believe that the subjects they teach have a lot of visual content; in question Q6, the most participants (73,5\%) answer that it is difficult to present visual content to the visually impaired, so that they have the same benefit as other people; and in question Q7 the most answers (77,9\%) was in agreement with the statement that it is difficult for the visually impaired to learn such content.

Some alternative ways of presenting visual contents for the blind people cited in question 8 were: textual description (cited by $75 \%$ of the participants), alternative audiobased content development (cited by $30,9 \%$ of the participants), graphical image tactile 
VIII Congresso Brasileiro de Informática na Educação (CBIE 2019)

Anais do XXX Simpósio Brasileiro de Informática na Educação (SBIE 2019)

representation development (cited by $29,4 \%$ of the participants), Braille image tactile representation development (cited by $13,2 \%$ of participants) and items related to materials for people with low vision such as image enlargement, color change, magnifying glasses, among others.

In question Q9, most survey participants $(73,5 \%)$ answered that they did not know many auxiliary tools for visually impaired people And for question Q10, the vast majority of survey participants (approximately 88\%) did not agree that the visual content auxiliary tools for visually impaired are widespread.

Besides these questions, the participant could specify tools which he (or she) knew. Two types of tools were mentioned. The first were general purpose tools such as: screen readers, in which they cited the software Dosvox ${ }^{1}, \mathrm{NVDA}^{2}, \mathrm{JAWS}^{3}, \mathrm{ORCA}^{4}$ and Virtual Vision ${ }^{5}$; Braille tools like Braille Fácil [Borges and Chagas Jr 2001]; and digital magnifying glasses.

In the second case, assistance tools for specific disciplines were mentioned, such as: Model2gether [Luque et al. 2016], which is a tool that supports collaborative modeling involving blind people (currently with the Unified Modeling Language diagrams module implemented) and NetAnimations [Bine and Martimiano 2018, Svaigen and Martimiano 2018] which are accessible animations for visually impaired people, that support the teaching-learning process in the computer networks subject.

\subsection{Students study}

For VI students, we applied the same methodology as in the previous case. Ten VI answered the questionnaire. A VI profile overview is presented in Fig. 3. As well as in the teacher scenario, most of them are from southern Brazil (70\%). Southeast, northeast and middle-west are still represented (10\% each). $50 \%$ are in public university, being undergraduated students. The knowledge areas among the participants are heterogeneous, with a smooth predominance of Exact and Earth Sciences (30\%).

The participants answered 3 questions related to teacher's didactic in teachinglearning experiences, listed as follows:

- Q1: I believe that teachers have didactic to VI teaching-learning;

- Q2: I believe that teachers are concerned in to adapt the classes content to VIs;

- Q3: I believe that teacher's academic background contemplates teaching-learning methodologies to attend VIs;

Regarding the visual content presented in subjects, VIs answered 4 questions:

- Q4: The subjects I studied had a great variety of visual content.

- Q5: I believe that I could get the same knowledge of these contents comparing to sighted students.

- Q6: I find that is pretty difficult to learn about a certain subject expressed by visual content.

\footnotetext{
${ }^{1}$ http://intervox.nce.ufrj.br/dosvox/

${ }^{2}$ https://www.nvaccess.org/

${ }^{3}$ https://www.freedomscientific.com/products/software/jaws/

${ }^{4}$ https://help.gnome.org/users/orca/stable/

${ }^{5}$ https://www.virtualvision.com.br/
} 


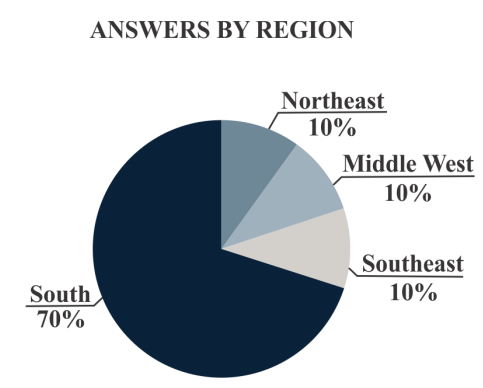

$\mathbf{a}$

ANSWERS BY OCCUPATION AREA

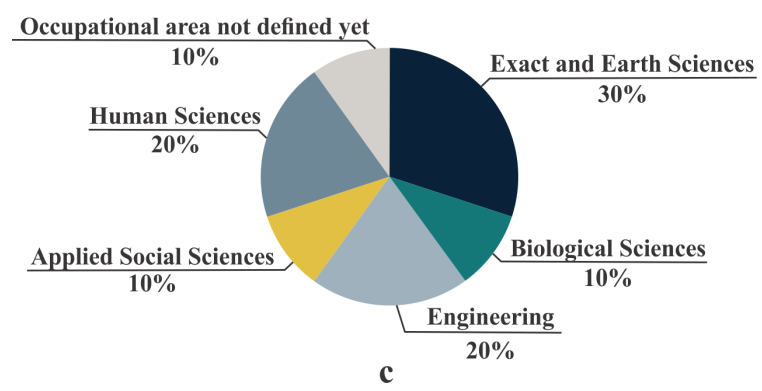

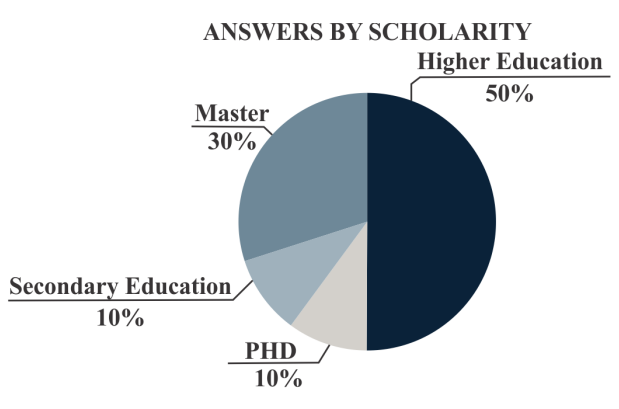

b

ANSWERS BY EDUCATIONAL ENVIRONMENT

Figure 3. VIs Profile Overview

- Q7: Which alternative representations did you use to learn visual contents?

We also asked about the participant's expertise of assistive tools which can aid the visual content understanding. The questions are presented as follows.

- Q8: I find that I have a good knowledge regarding assistive tools which aid visual content representation;

- Q9: I find that these tools are widely widespread in educational scope;

Besides these questions, the participant could specify tools which he (or she) knew. Figure 4 presented the VI's answers regarding the aforementioned questions.

The chart shows a similar scenario in Q1 and Q2 questions. The VIs mostly disagreed with teacher's didactic and their inclusive concernment. If we analyze these questions with Teacher's Q2, it is possible to note that the teachers' beliefs regarding their own didactic are quite similar to what VIs perceive. In Q3, VIs indicated a strong disagreement, in which there were not participants which agreed that teacher's academic background prepared them to VIs's teaching-learning. Again, if we compare this result with Teachers's Q3, the beliefs are similar.

The resemblance among all these question is an interesting point to observe. It indicates that teachers possibly have difficulties to teach VIs and they are perceiving this. In addition, there is a lack of didactic theoretical knowledge, mainly regarding teachers which are not graduated in Educational area.

In questions related to visual content presented in subjects, VIs indicated that subjects had some variety of visual content. However, $30 \%$ remained neutral, which can be explained by the heterogeneity of VIs occupation area. For instance, VIs related to 
VIII Congresso Brasileiro de Informática na Educação (CBIE 2019)

Anais do XXX Simpósio Brasileiro de Informática na Educação (SBIE 2019)

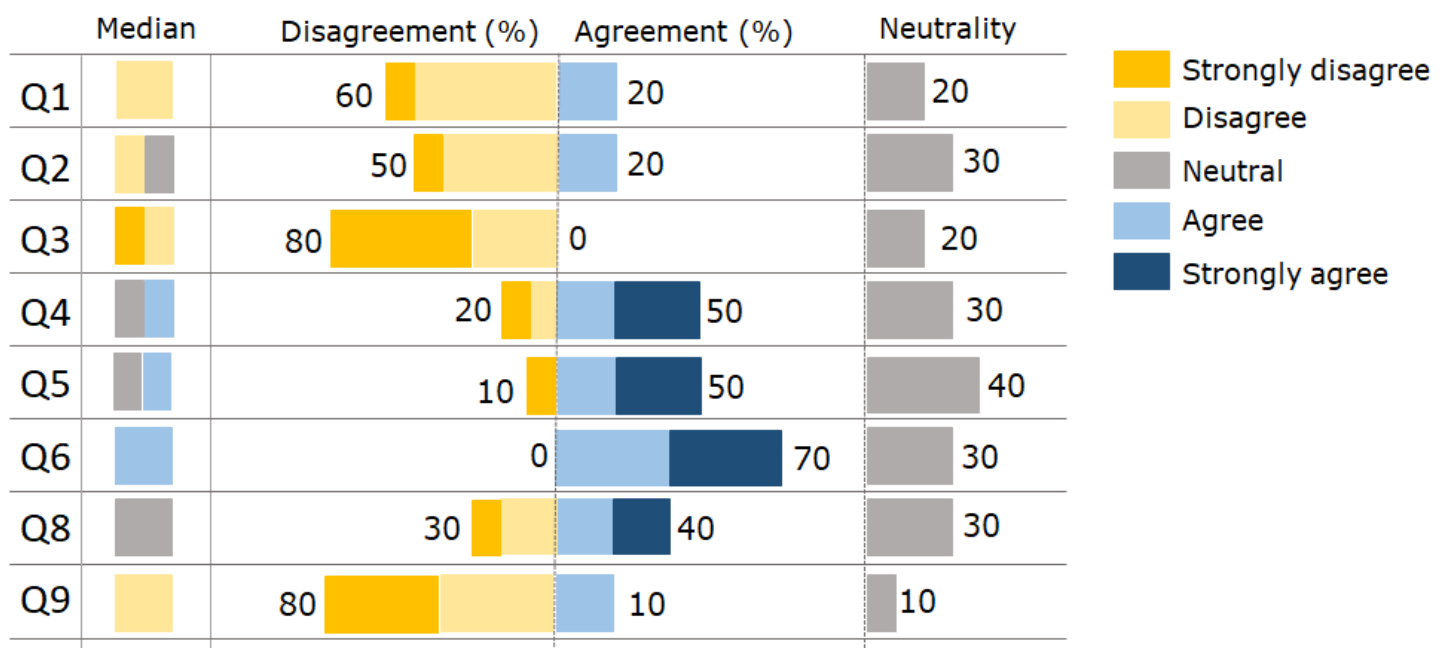

Figure 4. Vl's questionnaire answers

Engineering could have more visual content in their subjects than human sciences.

An interesting aspect was perceived in Q5: VIs mostly agreed that they could get the same knowledge comparing to sighted students, besides all difficulties. This belief meets several similar comments pointed by teacher regarding their experiences, where they related that VI students are extremely dedicated in order to learn comparing sighted students.

A concisely agreed response was obtained in Q6. VIs pointed that is pretty difficult to learn about visual content. Thus, if they consider they could get the same knowledge as sighted students and there is a difficult to obtain this knowledge, VIs probably must to expend more efforts to study visual concepts. Regarding Q7, textual representation provided by an audictory way and tactile representation were the most cited (30\% each). It was also pointed screen magnifiers softwares which provides a augmented representation for VIs with low vision.

In the last two questions, VIs could treat their expertise of assistive tools. They were neutral when asked about their knowledge regarding assistive tools which aid visual content representation and they did not agree that these assistive tools are widespread in educational scope. If we analyze these two information together, the neutrality in Q8 can be associated to the few widespread of these technologies, and on this way, the VIs need to search the knowledge about them in other sources, e.g., the Internet.

The tools specified by VIs after Q9 reply were, generally, digital magnifying glasses, high contrast screen and screen reader softwares, e.g., ORCA and NVDA. There was also cited tactile material with raised dots, being similar to Braille representation.

\section{Challenges}

In the last years, VIs' assistive tools which use 3D and/or haptic technology have been developed [Kim and Yeh 2015, Braier et al. 2015, Reusser et al. 2019]. Although the questionnaires represent a part of the scenario investigated, some intrinsic indications of why these technologies were not mentioned are the high cost of acquire them (and, consequently, use them) and the knowledge's lack about their existence. 
These two points are challenges to be overcome. Regarding the cost issue, a track to be followed are "Do it yourself" (DiY) technologies. In this approach, a tool (or a technology) can be developed according to the user preferences, following guideliness. DiY solutions contribute directly to low cost technologies and their popularization.

To the knowledge's lack regarding these tools, their popularization is a great challenge, not only for 3D and haptic technologies, but for all assistive tools developed. It was noted that a large part of the teachers' and students' responses about alternative image representations were textual description and handcrafted tactile materials.

Thus, how could we spread the existing assistive tools? One possible solution is to provide an online assistive tools catalog, sorting them by educational area and expose these data freely to VI students, teachers and other interested people, which can obtain these knowledge and contribute with the catalog.

This lead us to another challenge: the production of assistive technologies that are not only accessible, easy to use and have usability, but which also arouse the interest of its use by teachers and VIs. For example, how to show that it is more interesting to use software that produces a description of a figure automatically than to manually translate the material used?

Another challenge to be quoted is how to prepare teachers in order to improve their knowledge and didactic to teach students with different impairments, e.g., visual and auditory? This might be the most challenging issue among all presented in this work. Improve the aforementioned aspects involves to change the teachers' formation and, consequently, to change a learning paradigm.

There are several challenges which could be raised based on the notes provided by the questionnaires presented in Section 2. Their solutions still remain as opened questions, demanding extensive investigations. We consider that treating these issues, there will be great advancements in teaching-learning process regarding VIs, providing to them and to teachers also - a better learning environment, improving social, motivational and affective aspects.

\section{Conclusion}

This work presented an survey-based study of VIs teaching-learning process related to visual content. The study were carried out through questionnaires that sought to understand the teachers and VI students experiences in this scenario whose widespread follows the snowballing approach.

We obtained 78 replies, 68 teachers and 10 VI students. Analyzing these replies, a set of issues could be summarized, presented as follows:

- Teachers' didactic improves after experiences with VIs;

- Teachers and VIs mostly agreed that visual contents are difficult to teach and to learn;

- Teachers' academic background does not contemplates teaching-learning methodologies to attend properly VI issues, and they are perceiving this lack;

- Assistive technologies are not widely disseminated in educational environments.

It is important to say that these issues are just an indicative of teaching-learning 
VIII Congresso Brasileiro de Informática na Educação (CBIE 2019)

Anais do XXX Simpósio Brasileiro de Informática na Educação (SBIE 2019)

scenario treated, and it is not necessarily a complete reflection of all areas of knowledge, being necessary a wide statistical study to improve the comprehensiveness of them.

It was also presented challenges regarding assistive technology and their relationship with learning environments. These challenges still remains as opened questions to be solved:

- Dissemination of assistive tools developed by the academic community;

- The monetary cost and popularization of 3D and haptic technologies;

- The creation of tools that arouse the users' interests;

- And the preparation of teachers to teach students with disabilities;

In order to collaborate with this process, in future works we intend to elaborate a catalog with the assistive tools already developed and make them available online. The result of this process can not only contribute to the popularization of tools but also has the potential to assist teachers who have had not the experience of teaching visually impaired students yet.

\section{Acknowledgements}

This study was financed in part by the Coordenação de Aperfeiçoamento de Pessoal de Nível Superior - Brasil (CAPES) - Finance Code 001 and in part by the Conselho Nacional de Desenvolvimento Científico e Tecnológico - Brasil (CNPq).

\section{References}

Bhowmick, A. and Hazarika, S. M. (2017). An insight into assistive technology for the visually impaired and blind people: state-of-the-art and future trends. Journal on Multimodal User Interfaces, 11(2):149-172.

Bine, L. M. S. and Martimiano, L. A. F. (2018). Digital inclusion through the insertion of acessibility in the netanimations online repository. IEEE Latin America Transactions, 16(1):240-247.

Borges, J. A. and Chagas Jr, G. J. F. (2001). Impressão braille no brasil: o papel do braivox, braille fácil e pintor braille. I Simósio Brasileiro sobre Sistema Braille.

Braier, J., Lattenkamp, K., Räthel, B., Schering, S., Wojatzki, M., and Weyers, B. (2015). Haptic $3 \mathrm{~d}$ surface representation of table-based data for people with visual impairments. ACM Transactions on Accessible Computing (TACCESS), 6(1):1:1-1:35.

Brasil (1988). Constituição da república federativa do brasil. 292 p.

Goodman, L. A. (1961). Snowball sampling. The annals of mathematical statistics, pages $148-170$.

Kim, J. and Yeh, T. (2015). Toward 3d-printed movable tactile pictures for children with visual impairments. In Proceedings of the 33rd Annual ACM Conference on Human Factors in Computing Systems, pages 2815-2824. ACM.

Likert, R. (1932). A technique for the measurement of attitudes. Archives of psychology.

Luque, L., de Oliveira Brandão, L., Kira, E., Alves, A., and Brandão, F. (2017). Inclusion in computing and engineering education: Perceptions and learning in diagram-based e-learning classes with blind and sighted learners. In Proceedings..., pages 1-8, Indianapolis. IEEE Frontiers in Education Conference (FIE), 2017. 
VIII Congresso Brasileiro de Informática na Educação (CBIE 2019)

Anais do XXX Simpósio Brasileiro de Informática na Educação (SBIE 2019)

Luque, L., Santos, C., Cruz, D. O., Brandao, L. O., and Brandao, A. (2016). Model2gether: a tool to support cooperative modeling involving blind people. In Brazilian Conference of Software.

Pansanato, L. T. E., Bandeira, A. L. M., Santos, L. G. d., and Pereira, D. d. P. (2012). Projeto d4all: acesso e manipulação de diagramas por pessoas com deficiência visual. In Proceedings..., pages 33-36, Cuiabá. Brazilian Symposium on Human Factors in Computing Systems,11,2012, Brazilian Computer Society.

Reusser, D., Knoop, E., Siegwart, R., and Beardsley, P. (2019). Feeling fireworks: An inclusive tactile firework display. In Proceedings of the 2019 CHI Conference on Human Factors in Computing Systems, page 429. ACM.

Svaigen, A. R. and Martimiano, L. A. F. (2018). Netanimations mobile app: Improvement of accessibility and usability to computer network learning animations. IEEE Latin America Transactions, 16(1):272-278.

Teixeira, A. P. P. (2014). Acessibilidade digital para a educação inclusiva: desafios e oportunidades. Diálogo, (27):97-107. 